\title{
The expression of metastasis-associated in colon cancer-1 and KAl1 in gastric adenocarcinoma and their clinical significance
}

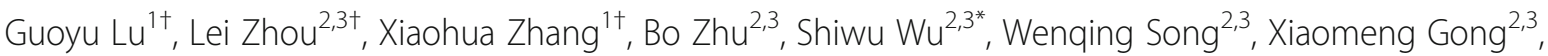 \\ Danna Wang ${ }^{2,3}$ and Yanyan Tao ${ }^{1}$
}

\begin{abstract}
Background: The most common reason for malignant tumor treatment failure is recurrence and metastasis. Metastasis-associated in colon cancer-1 (MACC1) was originally identified as a metastatic and prognostic biomarker for colon cancer and later other solid tumors. Kangai 1 (KAl1), a marker of suppressor of metastasis, is also associated with metastasis and poor prognosis in many tumors. However, the prognostic value of either MACC1 or KAl1 in gastric adenocarcinoma (GAC) is unclear. In this study, we explored the relationship between MACC1 and KAl1 expression, as well as their respective correlation with clinicopathological features, to determine if either could be helpful for improvement of survival prognosis in GAC patients.

Methods: The expression levels of both MACC1 and KAl1 in 325 whole-tissue sections of GAC were examined by immunohistochemistry. Clinical data was also collected.

Results: MACC1 was significantly overexpressed in GAC tissues when compared to levels in normal gastric tissues; KAl1 was significantly down-expressed in GAC tissues when compared to levels in normal gastric tissues. Investigation of association between MACC1 and KAl1 protein levels with clinicopathological parameters of GAC indicated association between the expression of each with tumor grade, lymph node metastasis, invasive depth, and TNM stages. The overall survival time of patients with MACC1- or KAl1-positive GAC tumors was significantly shorter or longer than that of those who were negative. Importantly, multivariate analysis suggested that positive expression of either MACC1 or KAI1, as well as TNM stage, could be independent prognostic factors for overall survival in patients with GAC.
\end{abstract}

Conclusions: MACC1 and KAl1 may represent promising metastatic and prognostic biomarkers, as well as potential therapeutic targets, for GAC.

Keywords: Gastric adenocarcinoma, MACC1, KAl1, Metastasis, Prognosis

\footnotetext{
*Correspondence: 573448542@qq.com

${ }^{\dagger}$ Equal contributors

2Department of Pathology, the First Affiliated Hospital of Bengbu Medical

College, No.287, Changhuai Road, Bengbu, China

${ }^{3}$ Department of Pathology, Bengbu Medical College, No.2600, Donghai

Street, Anhui Province, China

Full list of author information is available at the end of the article
} 


\section{Background}

There were approximately 950,000 new stomach cancer cases and 720,000 deaths that occurred in 2012 worldwide [1]. In general, China is one of the highest incidence countries worldwide [1]. Gastric adenocarcinoma (GAC) accounts for approximately $90 \%$ of all diagnosed stomach cancers. It was also one of the most frequent causes of cancer-related deaths. The 5-year survival rate is less than $5 \%$ for GAC patients with distant metastasis, as well as is less than $60 \%$ for patients with only localized malignancies [2]. In China, the majority of patients diagnosed with GAC have advanced stages of disease and are unsuitable for curative surgery.

Tumor recurrence and metastasis are the most common cause of treatment failure. Tumor recurrence and metastasis involve in multiple steps with a high degree of complexity and require the contribution of many molecules. Metastasis-associated in colon cancer-1 (MACC1) is a gene which contributes to these processes. MACC1 was first identified in colon cancer in 2009 and was bound to the promoter of the mesenchymal-epithelial transition (MET) gene to control its transcriptional activity [3, 4]. In vitro, MACC1 may drive proliferation, migration, invasion, and dissemination [5]; in vivo, it may regulate gene transcriptionally for metastasis, such as tyrosine kinase MET [5-7]. Furthermore, accumulating evidence has indicated that MACC1 should contribute to apoptosis and epithelial-mesenchymal transition (EMT) via hepatocyte growth factor/mesenchymal-epithelial transition (HGF/ MET) pathways [8]. MACC1 was also considered as a decisive driver for metastasis and tumorigenesis [9]. MACC1 was also an independent prognostic factor for colon cancer $[3,5]$. Now, more and more studies have demonstrated that MACC1 could also be a metastatic and prognostic factor for various human cancers, including pancreatic [10], liver [11], lung [12], ovary [13], breast [14], gastric [8], malignant glioma [15], and cervical carcinoma [16].

Kangai 1 (KAI1) was first identified as a suppressor of metastasis gene in prostate carcinoma [17]. KAI1 protein which is located in human chromosome 11p11.2 is a member of the transmembrane 4 superfamily (TM4SF). KAI1 can regulate signal transduction both cells to cells and cells to extracellular matrix (ECM) [18] and involve in some fundamental biological processes such as fusion, migration, adhesion, fertilization, differentiation, and invasion $[19,20]$. Accumulating evidence has demonstrated that decreased or lost KAI1 expression should associate with metastasis and prognosis in various tumors, including laryngeal carcinoma [20], prostate carcinoma [19, 21], breast carcinoma [22], lung carcinoma [23], gastric carcinoma [24], colon carcinoma [25], and hepatocellular carcinoma [26].

The involvement of MACC1 and KAI1 in the recurrence and metastasis of GAC suggests that they should be valuable biomarkers for measuring cancer progression and developing higher accurately therapeutic targets. To our knowledge, a correlation between MACC1 and KAI1 in GAC has not yet been reported. In this study, we detected the association between MACC1 and KAI1 expression in patient cancer tissues as well as compared their expression with clinicopathology, metastasis, and prognosis of GAC.

\section{Methods \\ Biopsy specimens}

GAC tissues and adjacent noncancerous gastric tissues were collected at the Department of Pathology of the First Affiliated Hospital of Bengbu Medical College, from January 2008 to December 2010. Patients who had received preoperative chemo- or radio-therapy were excluded. All tissue specimens were obtained with patient consent, and the research was approved by the ethical committee of Bengbu Medical College and conducted in accordance with the ethical guidelines of the Declaration of Helsinki. The adjacent noncancerous gastric tissues were removed from the same patient, avoiding necrotic tissue, and from surrounding gastric tissue at least $5 \mathrm{~cm}$ away from the carcinoma edge. The research group consisted of 325 patients, 214 males and 111 females, aged from 26 to 78 years; the average age was $57.7 \pm 10.9$ years. All patients who had completely clinical, pathological, and follow-up (at 8-month intervals by phone, mail, or email) data were sporadic cases. Overall survival (OS) time was collected from surgery to death or December 2015 (mean OS time 42.0 months; range 8-95 months). Tumor node metastasis stage was evaluated according to the 7 th edition of the American Joint Committee on Cancer (AJCC). Grade of tumor differentiation was according to the World Health Organization (WHO) standard.

Please contact author for data requests.

\section{Immunohistochemistry}

All GAC and corresponding normal gastric tissues were fixed in $10 \%$ buffered formalin and embedded in paraffin. Then continuous 4- $\mu$ m-thick tissue sections were cut. Subsequently, all sections were deparaffinized and dehydrated with xylene, graded ethanol, and washed for 10 min in PBS (pH 7.2). Immunohistochemistry was performed according to the Elivision Plus detection kit instructions (Lab Vision, USA). Endogenous peroxidase activity was blocked by incubation of sections in methanol containing $3 \% \mathrm{H}_{2} \mathrm{O}_{2}$ for $10 \mathrm{~min}$ at room temperature, then placed in citrate buffer $(\mathrm{pH} \mathrm{6.0)}$ and heated to $95{ }^{\circ} \mathrm{C}$ for $30 \mathrm{~min}$ for antigen repair. After several washes in PBS, the sections were quenched with goat serum for $20 \mathrm{~min}$ at room temperature, then incubated with rabbit polyclonal antibody against human 
MACC1 (Santa Cruz Biotechnology, Santa Cruz, CA, USA) or mouse monoclonal antibody against human KAI1 (Abcam, Cambridge, MA, USA) for $1 \mathrm{~h}$ at $37^{\circ} \mathrm{C}$. All sections were counterstained with hematoxylin, dehydrated, air-dried, and mounted. Negative controls were prepared by deleting primary antibodies from the staining procedure. MACC1-positive staining was mainly confined in the cytoplasm of cancer cells, and KAI1positive staining was mainly confined in the membrane and cytoplasm of cancer cells.

\section{Evaluation of staining}

Staining results were evaluated by two experienced pathologists who were blind to the clinical data and assessed by semi-quantitative scores. Because of intratumoral heterogeneity of antibody expression, we randomly chose ten visual fields from different areas of each section of GAC. If there was a disagreement, the pathologists would reexamine the immunostaining and reach a consensus [27-29]. To assess MACC1 and KAI1 expression, both the extent and intensity of immunostaining were thought [27]. The staining extent score was graded as follows: none, 0; weak, 1; moderate, 2; and strong, 3. The intensity of positive staining was graded as follows: $<10 \%, 1 ; 11-50 \%, 2$; $51-75 \%, 3$; and $>75 \%, 4$. Then the score was determined by multiplying the extent and intensity of immunostaining to reach a range of scores from 0 to 12 . For tumors that were positive for both MACC1 and KAI1, an average of the final of each sample was taken. Immunostaining was thought positive when the score was $\geq 3$.

\section{Statistical analysis}

Relationship between either MACC1- or KAI1 protein expression and clinicopathological parameters were compared using Fisher's exact test or chi-square test. The correlation between MACC1 and KAI1 expression was compared using Spearman's coefficient test. The effects of MACC1 and KAI1 expression on OS time were determined using Kaplan-Meier method for univariate analysis. Independent prognostic indicators were determined using the Cox regression model for multivariate analysis. The association between the positive expression of either MACC1 or KAI1 and clinicopathological parameters was determined using SPSS 19.0 software for Windows (Chicago, IL). A value of $P<0.05$ was determined as statistically significant.

\section{Results}

All GAC patient clinicopathological characteristics could be seen in Table 1 .
Table 1 Patients characteristics

\begin{tabular}{|c|c|c|}
\hline Patients characteristics & Frequency $(n)$ & Percentage (\%) \\
\hline \multicolumn{3}{|l|}{ Gender } \\
\hline Male & 214 & 65.8 \\
\hline Female & 111 & 34.2 \\
\hline \multicolumn{3}{|l|}{ Ages } \\
\hline$<58$ & 140 & 43.1 \\
\hline$\geq 58$ & 185 & 56.9 \\
\hline \multicolumn{3}{|l|}{ Gross type } \\
\hline Polypoid & 37 & 11.4 \\
\hline Ulcerative & 220 & 67.7 \\
\hline Invasive & 68 & 20.9 \\
\hline \multicolumn{3}{|l|}{ Location } \\
\hline Antrum & 163 & 50.2 \\
\hline Cardia & 118 & 36.3 \\
\hline Pylorus & 44 & 13.5 \\
\hline \multicolumn{3}{|l|}{ Size } \\
\hline$D<4.0 \mathrm{~cm}$ & 75 & 23.1 \\
\hline $4.0 \mathrm{~cm} \leq D<8.0 \mathrm{~cm}$ & 211 & 64.9 \\
\hline $8.0 \mathrm{~cm} \leq D$ & 39 & 12.0 \\
\hline \multicolumn{3}{|l|}{ Depth of invasion } \\
\hline Submucosa & 21 & 6.5 \\
\hline Subserosa & 100 & 30.8 \\
\hline Visceral peritoneum & 184 & 56.6 \\
\hline Adjacent structures & 20 & 6.2 \\
\hline \multicolumn{3}{|l|}{ Tumor grade } \\
\hline Well & 47 & 14.5 \\
\hline Moderate & 204 & 62.8 \\
\hline Poor & 74 & 22.8 \\
\hline \multicolumn{3}{|l|}{ Lymph node metastasis } \\
\hline No & 178 & 54.8 \\
\hline Yes & 147 & 45.2 \\
\hline \multicolumn{3}{|l|}{ TNM stage } \\
\hline | and || & 153 & 47.1 \\
\hline III and IV & 172 & 52.9 \\
\hline
\end{tabular}

\section{Expression of MACC1 and KAI1 in GAC and their association with clinicopathology}

To assess the contributions of MACC1 and KAI1 to GAC, their expression levels were evaluated in both GAC and normal gastric tissue slides using immunohistochemistry. MACC1-positive staining was mainly confined in the cytoplasm of cancer cells, and KAI1-positive staining was mainly confined in the membrane and cytoplasm of cancer cells. These data were compared to clinicopathological characteristics. The positive rate of MACC1 protein expression was $60.3 \%(196 / 325)$ in 
GAC tissues and $9.2 \%(30 / 325)$ in normal gastric tissues (Fig. 1a, b), and this difference was shown to be statistically significant $(P<0.01)$. There were also significant differences between the expression of MACC1 and tumor grade $(P=0.009)$, size of tumor $(P=0.009)$, invasion of depth $(P<0.001)$, lymph node metastasis (LNM) $(P<0.001)$, and tumor-node-metastasis (TNM) $(P<0.001)$. In contrast, there were no associations detected between MACC1 expression and patient age $(P=0.295)$, gender $(P=0.482)$, location $(P=0.072)$, and gross type $(P=0.108)$.

In contrast to MACC1 expression, the expression of KAI1 was significantly lower in GAC than in control tissues, with positive rates of $41.2 \%(134 / 325)$ and $92.3 \%$ $(300 / 325)$, respectively $(P<0.01)$ (Fig. $1 \mathrm{c}, \mathrm{d})$. There were also negative associations between expression of KAI1 in GAC and tumor grades $(P=0.045)$, invasion of depth $(P$ $<0.001)$, lymph node metastasis $(P=0.016)$, and TNM stage $(P<0.001)$. There were no relationships detected between KAI1 expression and patient age $(P=0.079)$, gender $(P=0.065)$, size of tumor $(P=0.354)$, location $(P=0.372)$, and gross type $(P=0.965)$ (Table 2$)$. Spearman correlation coefficient analysis demonstrated a negative correlation between the expression of MACC1 and KAI1 $(\mathrm{r}=-0.240, P<0.001)$ (Table 2$)$.

\section{Univariate analysis}

Follow-up data indicated that overall survival time was significantly decreased in GAC patients with positive expression of MACC1 (32.7 months) compared to those who were MACC1-negative (56.1 months) (log-rank= 46.375, $P<0.001$ ) (Fig. 2a). On the contrast, the OS time of KAI1-positive patients (52.6 months) was significantly longer than those tumors which were negative (34.5 months) (log-rank $=25.422, P<0.001)$ (Fig. 2b). In the univariate analysis, OS time was significantly related to clinicopathological characteristics, such as tumor diameter $(P=0.033$, log-rank $=6.844)$, invasion of depth $(P<0.001$, log-rank $=26.806)$, LNM $(P<0.001$, log-rank $=75.925)$, and TNM stage $(P<0.001$, log-rank $=158.587)($ Table 3$)$.

\section{Multivariate analysis}

Multivariate analysis demonstrated that positive expression of either MACC1 or KAI1, as well as TNM stage, was an independent prognostic indicator for GAC (Table 4).

\section{Discussion}

Gastric adenocarcinoma (GAC) is a highly heterogeneous tumor. This heterogeneity may affect the reproducibility of biomarker evaluation $[5,30]$. So, thorough investigation of the metastatic and prognostic values of a candidate biomarker is thus required to ensure validity. In our study, we investigated MACC1 expression in GAC and matched normal tissues from 325 patients and compared it to clinicopathological characteristics. We found that MACC1 expression was significantly higher

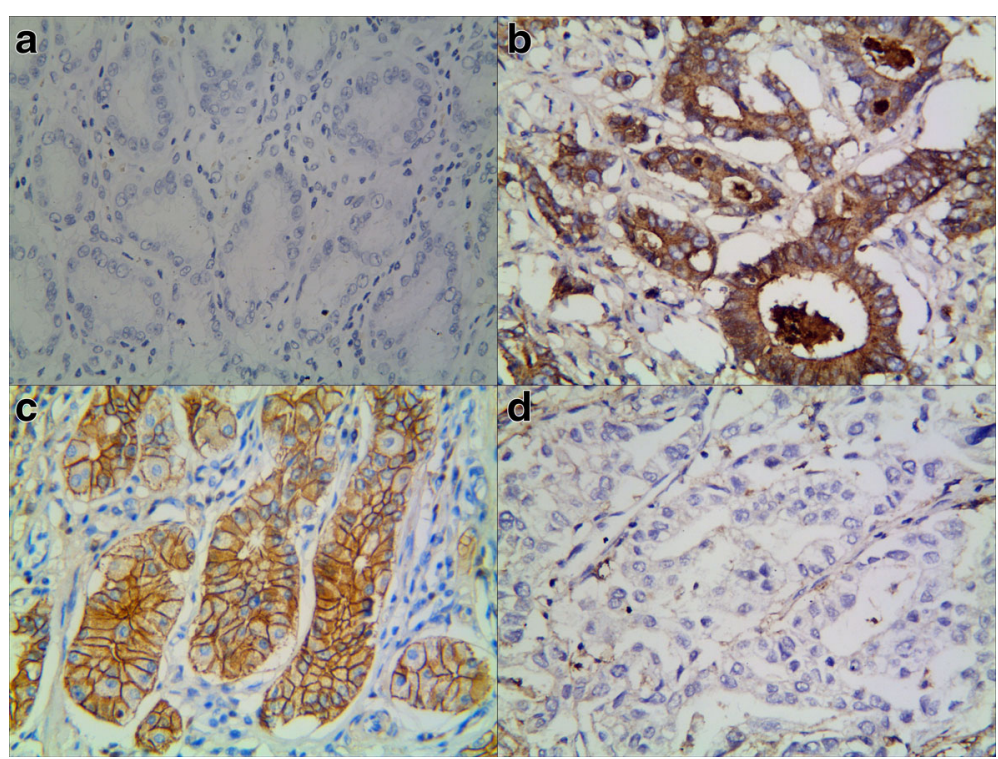

Fig. 1 Representative results of MACC1 and KAI1 in gastric adenocarcinoma and control group. a Control gastric epithelial cells not expressing MACC1. b MACC1 predominantly localized in the cytoplasm in moderate grade of gastric carcinoma (MACC1 ×400). c Control gastric epithelial cells expressing KAl1 in the membrane and cytoplasm. $\mathbf{d}$ Moderate grade of gastric carcinoma cells not expressing KAl1 (KAl1 $\times 400)(\mathbf{b}$ and $\mathbf{d}$ are the same GAC patient's slice) 
Table 2 The association between the expression of MACC1 or KAl1 and clinicopathological characteristics in gastric adenocarcinoma

\begin{tabular}{|c|c|c|c|c|c|c|}
\hline \multirow[t]{2}{*}{ Variable } & \multicolumn{2}{|l|}{ MACC1 } & \multirow[t]{2}{*}{$P$ value } & \multicolumn{2}{|l|}{ KAl1 } & \multirow[t]{2}{*}{$P$ value } \\
\hline & Negative & Positive & & Negative & Positive & \\
\hline Gender & & & 0.482 & & & 0.065 \\
\hline Male & 82 & 132 & & 118 & 96 & \\
\hline Female & 47 & 64 & & 73 & 38 & \\
\hline Ages & & & 0.295 & & & 0.079 \\
\hline$<58$ & 51 & 89 & & 90 & 50 & \\
\hline$\geq 58$ & 78 & 107 & & 101 & 84 & \\
\hline Gross type & & & 0.108 & & & 0.965 \\
\hline Polypoid & 20 & 17 & & 21 & 16 & \\
\hline Ulcerative & 80 & 140 & & 130 & 90 & \\
\hline Invasive & 29 & 39 & & 40 & 28 & \\
\hline Location & & & 0.072 & & & 0.372 \\
\hline Antrum & 64 & 99 & & 92 & 71 & \\
\hline Cardia & 41 & 77 & & 69 & 49 & \\
\hline Pylorus & 24 & 20 & & 30 & 14 & \\
\hline Size & & & 0.009 & & & 0.354 \\
\hline$D<4.0 \mathrm{~cm}$ & 35 & 40 & & 42 & 33 & \\
\hline $4.0 \mathrm{~cm} \leq D<8.0 \mathrm{~cm}$ & 87 & 124 & & 122 & 89 & \\
\hline $8.0 \mathrm{~cm} \leq D$ & 7 & 32 & & 27 & 12 & \\
\hline Depth of invasion & & & $<0.001$ & & & $<0.001$ \\
\hline Submucosa & 13 & 8 & & 9 & 12 & \\
\hline Subserosa & 53 & 47 & & 43 & 57 & \\
\hline Visceral peritoneum & 59 & 125 & & 122 & 62 & \\
\hline Adjacent structures & 4 & 16 & & 17 & 3 & \\
\hline Tumor grade & & & 0.009 & & & 0.045 \\
\hline Well & 20 & 27 & & 21 & 26 & \\
\hline Moderate & 91 & 113 & & 120 & 84 & \\
\hline Poor & 18 & 56 & & 50 & 24 & \\
\hline Lymph node metastasis & & & $<0.001$ & & & 0.016 \\
\hline No & 93 & 85 & & 94 & 84 & \\
\hline Yes & 36 & 111 & & 97 & 50 & \\
\hline TNM stage & & & $<0.001$ & & & $<0.001$ \\
\hline | and || & 96 & 57 & & 71 & 82 & \\
\hline III and IV & 33 & 139 & & 120 & 52 & \\
\hline $\mathrm{KAl} 1^{\mathrm{a}}$ & & & $<0.001$ & & & \\
\hline Negative & 57 & 134 & & & & \\
\hline Positive & 72 & 62 & & & & \\
\hline
\end{tabular}

${ }^{\mathrm{a}}$ Negative relationship $(r=-0.240, P<0.001)$

in GAC tissues than that in the control tissues. Furthermore, MACC1 expression was positively correlated with tumor size, grade, invasion of depth, LNM, and TNM stage. Our results were consistent with those of previous studies in GAC $[8,31-33]$ demonstrating that
MACC1 should be useful as a clinical candidate biomarker of GAC.

KAI1, a cell membrane protein that binds to ECM or adhesion proteins [34, 35], is widely considered as a suppresser gene of metastasis in many cancers [19-26]. 

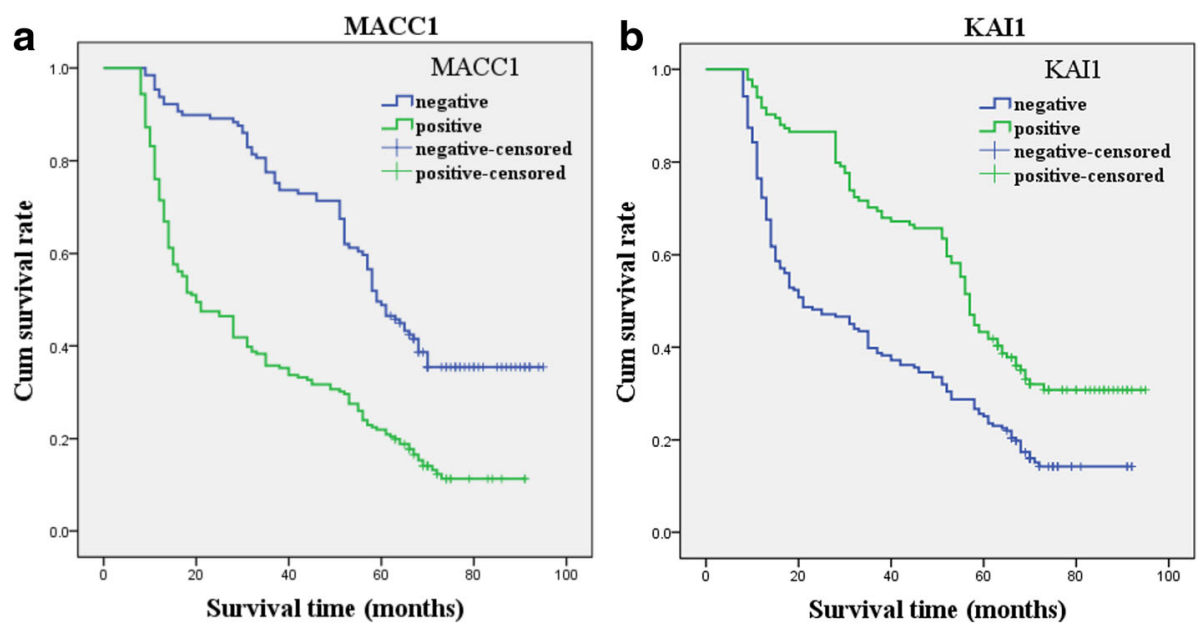

Fig. 2 Kaplan-Meier survival analysis by MACC1 and KAl1 status. The $y$-axis represents the percentage of patient; the $x$-axis, their survival in months. The green line represents patients with positive expression of MACC1 (a) or KAl1 (b) with a trend of worse or better survival time than the blue line representing the negative MACC1 group or KAl1 group $(P<0.001)$. Mean survival time was 32.7 months for the positive expression of the MACC1 group and 56.1 months for the negative MACC1 group. Mean survival time was 52.6 months for the positive expression of the KAl1 group and 34.5 months for the negative KAl1 group $(n=325)$

KAI1 has been correlated with carcinogenesis [20] and showed to predict a poor metastasis and prognosis [19-26]. In this study, we also found that KAI1 expression was significantly related to tumor grade, invasion of depth, LNM, and TNM stage. In addition, Kaplan-Meier survival analysis indicated that GAC patients with positive KAI1 expression had significantly increased survival time compared to those with negative KAI1. These results indicated that KAI1 should play a key role in tumorigenesis, invasion, metastasis, and prognosis of GAC. Several other immunohistochemical studies that investigated the metastatic and prognostic significance of KAI1 in GAC patients obtained similar results [24, 36, 37]. Thus, our results supported the conception that KAI1 should be a credible biomarker of GAC, especially for predicting metastasis and prognosis of cancers.

Metastasis and recurrence are the most common reasons of cancer-related deaths in GAC. TNM staging system is well-known as the guide for devising therapeutic strategies for patients with GAC. However, the TNM staging system cannot provide comprehensive information about the biological behavior of the cancer. Thus, it is urgent to seek novel and effective metastatic and prognostic biomarkers to predict biological behavior (metastasis and recurrence) in GAC patients. In our study, multivariate Cox model analysis showed that the positive expression of either MACC1 or KAI1, as well as TNM stage, was an independent prognostic indicator for patients with GAC.

In our study, we found that MACC1 expression was negatively correlated with KAI1 expression. Furthermore, we also found that there was a negative correlation between the high expression of MACC1 and low expression of KAI1 in the same GAC patient. Abnormal (decreased or lost) expression of KAI1 may be involved in the initiation, development, invasion, metastasis, and recurrence of GAC through lost of function of tumor suppressor gene or suppressor gene of tumor metastasis. Indeed, KAI1, as a suppressor of tumor metastasis, could inhibit $\beta$-catenin tyrosine phosphorylation and stabilize E-cadherin- $\beta$-catenin complexes to suppress tumor metastasis [38]. In addition, KAI1 could inhibit the process of $\beta$-catenin-mediated EMT to prevent tumor angiogenesis and lymphangiogenesis [39]. Meanwhile, MACC1 could be bound to the promoter of the MET gene and activate the HGF/MET signaling pathway to promote cancer cell proliferation, invasion, and metastasis $[3,4]$. Furthermore, it could promote angiogenesis and lymphangiogenesis to lead to cancer cell invasion and metastasis [40, 41]. Moreover, KAI1 is able to be bind to cMET to form a complex or quench the activation of HGF, thus preventing the activation of MACC1 to inhibit the migration of tumor cells [42, 43]. Decreased or lost expression of KAI1 might lose inhibiting the activation of MACC1, angiogenesis and lymphangiogenesis, and stabilization of Ecadherin- $\beta$-catenin complexes to promote cancer cell invasion and metastasis. At the same time, abnormal expression of MACC1 could further promote cancer cell invasion and metastasis. However, the methodology of subjects in our study was relatively simple; further studies with more methodologies (such as assessing the effect of target molecules on biological properties in vitro and in vivo models) are needed to verify the present observation. 
Table 3 Results of univariate analyses of overall survival (OS) time

\begin{tabular}{|c|c|c|c|c|}
\hline Variable & $n$ & Mean OS (months) & Log-rank & $P$ value \\
\hline$\overline{M A C C 1}$ & & & 46.375 & $<0.001$ \\
\hline Negative & 129 & $56.1 \pm 22.3$ & & \\
\hline Positive & 196 & $32.7 \pm 24.5$ & & \\
\hline KAl1 & & & 25.422 & $<0.001$ \\
\hline Negative & 191 & $34.5 \pm 25.6$ & & \\
\hline Positive & 134 & $52.6 \pm 23.4$ & & \\
\hline Gender & & & 0.187 & 0.666 \\
\hline Male & 214 & $42.5 \pm 26.2$ & & \\
\hline Female & 111 & $41.0 \pm 26.5$ & & \\
\hline Ages & & & 0.420 & 0.517 \\
\hline$<58$ & 140 & $41.6 \pm 27.2$ & & \\
\hline$\geq 58$ & 185 & $42.3 \pm 25.6$ & & \\
\hline Gross type & & & 0.541 & 0.763 \\
\hline Polypoid & 37 & $46.3 \pm 26.8$ & & \\
\hline Ulcerative & 220 & $41.7 \pm 26.1$ & & \\
\hline Invasive & 68 & $40.5 \pm 26.5$ & & \\
\hline Location & & & 5.536 & 0.063 \\
\hline Antrum & 163 & $41.4 \pm 26.5$ & & \\
\hline Cardia & 118 & $44.3 \pm 26.7$ & & \\
\hline Pylorus & 44 & $37.9 \pm 23.8$ & & \\
\hline Size & & & 6.844 & 0.033 \\
\hline$D<4.0 \mathrm{~cm}$ & 75 & $49.8 \pm 27.8$ & & \\
\hline $4.0 \mathrm{~cm} \leq D<8.0 \mathrm{~cm}$ & 211 & $40.0 \pm 25.5$ & & \\
\hline $8.0 \mathrm{~cm} \leq D$ & 39 & $38.4 \pm 25.0$ & & \\
\hline Depth of invasion & & & 26.806 & $<0.001$ \\
\hline Submucosa & 21 & $64.1 \pm 16.7$ & & \\
\hline Subserosa & 100 & $50.6 \pm 27.1$ & & \\
\hline Visceral peritoneum & 184 & $35.8 \pm 24.3$ & & \\
\hline Adjacent structures & 20 & $32.5 \pm 23.6$ & & \\
\hline Tumor grade & & & 2.576 & 0.276 \\
\hline Well & 47 & $47.0 \pm 32.6$ & & \\
\hline Moderate & 204 & $40.8 \pm 24.3$ & & \\
\hline Poor & 74 & $42.0 \pm 26.9$ & & \\
\hline LNM & & & 75.925 & $<0.001$ \\
\hline No & 178 & $53.4 \pm 24.1$ & & \\
\hline Yes & 147 & $28.2 \pm 21.8$ & & \\
\hline TNM stage & & & 158.587 & $<0.001$ \\
\hline | and || & 153 & $60.9 \pm 18.1$ & & \\
\hline III and IV & 172 & $25.2 \pm 20.2$ & & \\
\hline
\end{tabular}

Table 4 Results of multivariate analyses of overall survival (OS) time

\begin{tabular}{llllll}
\hline Covariate & \multicolumn{1}{l}{ B } & SE & $P$ & HR & $95 \% \mathrm{Cl}$ \\
\hline TNM stage & 1.277 & 0.181 & $<0.001$ & 3.585 & $2.513-5.112$ \\
MACC1 & 0.385 & 0.150 & 0.010 & 1.470 & $1.096-1.972$ \\
KAl1 & -0.434 & 0.141 & 0.002 & 0.648 & $0.492-0.854$
\end{tabular}

\section{Conclusions}

Our findings indicate that abnormal expression of MACC1 and KAI1 should play key roles in the development of GAC. The combined detection of MACC1 and KAI1 may be valuable as biomarkers for metastasis and thereby prognosis for patients with GAC.

\section{Abbreviation}

AJCC: American Joint Committee on Cancer; ECM: Extracellular matrix; EMT: Epithelial-mesenchymal transition; GAC: Gastric adenocarcinoma; HGF: Hepatocyte growth factor; KAl1: Kangai 1; LNM: Lymph node metastasis; MACC1: Metastasis-associated in colon cancer-1; MET: Mesenchymal-epithelial transition; OS: Overall survival; TM4SF: Transmembrane 4 superfamily; TNM: Tumor node metastasis; WHO: World Health Organization

\section{Acknowledgements}

Not applicable.

\section{Funding}

This work was supported by the Anhui Province Key Laboratory and Engineering Center (Bengbu Medical College) open issue plan (No. BYKL1412ZD) and the Nature Science Key Program of College and University of Anhui Province (No. KJ2015A269 and KJ2016A488) and key projects of support program for outstanding young talents in colleges and universities of Anhui Province (No. gxyqZD2016160).

\section{Availability of data and materials}

The datasets during and/or analyzed during the current study are available from the corresponding author on reasonable requests.

\section{Authors' contributions}

WSW, LGY, ZL, ZXH, and ZB carried out the design and analysis of pathology and drafted the manuscript. GXM and SWQ carried out sample collection and coordination. WDN and TYY performed the immunohistochemical staining. All authors read and approved the manuscript.

\section{Competing interests}

The authors declare that they have no competing interests.

\section{Consent for publication}

Not applicable.

\section{Ethics approval and consent to participate}

Tissue samples for diagnostic and research aims were obtained with each patient's consents, and the research was approved by the ethical committee of Bengbu Medical College and performed in accordance with the guidelines of the Declaration of Helsinki.

\section{Disclosure}

There are neither commercial interests nor financial and/or commercial support.

\section{Author details}

'Department of Emergence, The First Affiliated Hospital of Bengbu Medical College, No.287, Changhuai Road, Bengbu, China. ${ }^{2}$ Department of Pathology, the First Affiliated Hospital of Bengbu Medical College, No.287, Changhuai Road, Bengbu, China. ${ }^{3}$ Department of Pathology, Bengbu Medical College, No.2600, Donghai Street, Anhui Province, China. 
Received: 16 March 2016 Accepted: 21 October 2016

Published online: 28 October 2016

\section{References}

1. Torre LA, Bray F, Siegel RL, Ferlay J, Lortet-Tieulent J, Jemal A. Global cancer statistics, 2012. CA Cancer J Clin. 2015:65:87-108.

2. Catalano V, Labianca R, Beretta GD, Gatta G, de Braud F, Van Custsem E. Gastric cancer. Crit Rev Oncol Hematol 2005, 54: 209-41.

3. Stein U, Walther W, Arlt F, Schwabe H, Smith J, Fichtner I, et al. MACC1, a newly identified key regulator of HGF-MET signaling, predicts colon cancer metastasis. Nat Med. 2009;15:59-67.

4. Stein U, Smith J, Walther W, Arlt F. MACC1 controls Met: what a difference an Sp1 site makes. Cell Cycle. 2009;8:2467-9.

5. Koelzer VH, Herrmann P, Zlobec I, Karamitopoulou E, Luqli A, Stein U. Heterogeneity analysis of metastasis associated in colon cancer 1 (MACC1) for survival prognosis of colorectal cancer patients: a retrospective cohort study. BMC Cancer. 2015;15:160.

6. Chundong $\mathrm{G}$, Uramoto $\mathrm{H}$, Onitsuka T, Shimokawa H, Iwanami T, Nakagawa $\mathrm{M}$, et al. Molecular diagnosis of MACC1 status in lung adenocarcinoma by immunohistochemical analysis. Anticancer Res. 2011:31:1141-5.

7. Ren B, Zakharov V, Yang Q, McMahon L, Yu J, Cao W. MACC1 is related to colorectal cancer initiation and early-stage invasive growth. Am J Clin Pathol 2013, 140: 707-7.

8. Burock S, Herrmann P, Wendler I, Niederstrasser M, Wernecke KD, Stein U. Circulating metastasis associated in colon cancer 1 transcripts in gastric cancer patient plasma as diagnostic and prognostic biomarker. World J Gastroenterol. 2015;21:333-41.

9. Stein U. MACC1 - a novel target for solid cancers. Expert Opin Ther Targets. 2013;17:1039-52.

10. Wang G, Kang MX, Lu WJ, Chen Y, Zhang B, Wu YL. MACC1: a potential molecule associated with pancreatic cancer metastasis and chemoresistance. Oncol Lett. 2014;4:783-91.

11. Yang YP, Ou JH, Chang XJ, Lu YY, Bai WL, Dong Z, et al. High intratumoral metastasis-associated in colon cancer-1 expression predicts poor outcomes of cryoablation therapy for advanced hepatocellular carcinoma. J Transl Med. 2013;11:41

12. Wang $Z$, Li Z, Wu C, Wang $Y, X i a Y$, , Chen $L$, et al. MACC1 overexpression predicts a poor prognosis for non-small lung cancer. Med Oncol. 2014;31:790

13. Sheng XJ, Li Z, Sun M, Wang ZH, Zhou DM, Li JQ, et al. MACC1 induces metastasis in ovarian carcinoma by upregulating hepatocyte growth factor receptor c-MET. Oncol Lett. 2014;8:891-7.

14. Huang $Y$, Zhang $H$, Cai J, Fang $L, W u J, Y e ~ C$, et al. Overexpression of MACC1 and its significance in human breast cancer progression. Cell Biosci. 2013;3:16

15. Hagemann C, Fuchs S, Monoranu CM, Herrmann P, Smith J, Hohmann T, et al. Impact of MACC1 on human malignant glioma progression and patients unfavorable prognosis. Neuro Oncol. 2013;15:1696-709.

16. Guo L, Lu W, Zhang X, Luo D, Zhang H. Metastasis-associated colon cancer1 is a novel prognostic marker for cervical cancer. Int J Clin Exp Pathol. 2014:7:4150-5.

17. Dong JT, Lamb PW, Rinker-Schaeffer CW, Vukanovic J, Ichikawa T, Isaacs JT, et al. KAl1, a metastasis suppressor gene for prostate cancer on human chromosome 11p11.2. Science. 1995;268:884-6.

18. Bienstock RJ, Barrett JC. KAl1, a prostate metastasis suppressor: prediction of solvated structure and interactions with binding partners; integrins, cadherins and cell-surface receptor proteins. Mol Carcinog. 2001;32:139-53.

19. Miranti CK. Controlling cell surface dynamics and signaling: how CD82/KAl1 suppresses metastasis. Cell Signal. 2009;21:196-211.

20. Yu L, Zhou L, Wu S, Gong X, Feng Z, Ma L, et al. Clinicopathological significance of cancer stem cells marked by CD133 and KAl1/CD82 expression in laryngeal squamous cell carcinoma. World J Surg Oncol. 2014;12:118.

21. Liu W, liizumi-Gairani M, Okuda H, Kobayashi A, Watabe M, Pai SK, et al. KAl1 gene is engaged in NDRG1 gene-mediated metastasis suppression through the ATF3-NFkappaB complex in human prostate cancer. J Biol Chem. 2011; 286:18948-59.

22. Mooez S, Malik FA, Kayani MA, Rashid R, Zahid A, Khan A. Expressional alterations and transcript isoforms of metastasis suppressor genes (KAl1 and KiSS1) in breast cancer patients. Asian Pac J Cancer Prev. 2011;12:2785-91.

23. Goncharuk VN, del Rosario A, Kren L, Anwar S, Sheehan CE, Carlson JA, et al. Co-downregulation of PTEN, KAl-1, and nm23-H1 tumor/metastasis suppressor proteins in non-small cell lung cancer. Ann Diagn Pathol. 2004;8:6-16.
24. Chen Z, Gu S, Trojanowicz B, Liu N, Zhu G, Dralle H, et al. Down-regulation of TM4SF is associated with the metastatic potential of gastric carcinoma TM4SF members in gastric carcinoma. World J Surg Oncol. 2011;9:43.

25. Wu DH, Liu L, Chen LH, Ding YQ. KAl1 gene expression in colonic carcinoma and its clinical significances. World J Gastroenterol. 2004;10:2245-9.

26. Guo C, Liu QG, Zhang L, Song T, Yang X. Expression and clinical significance of p53, JunB and KAl1/CD82 in human hepatocellular carcinoma. Hepatobiliary Pancreat Dis Int. 2009;8:389-96.

27. Wu S, Yu L, Wang D, Zhou L, Cheng Z, Chai D, et al. Aberrant expression of CD133 in non-small cell lung cancer and its relationship to vasculogenic mimicry. BMC Cancer. 2012;12:535.

28. Lee KH, Ahn EJ, Oh SJ, Kim O, Joo YE, Bae JA, et al. Kitenin promotes glioma invasiveness and progression associated with the induction of EMT and stemness markers. Oncotarget. 2015;6:3240-53.

29. Li X, Xu Q, Fu X, Luo W. ALDH1A1 overexpression is associated with the progression and prognosis in gastric cancer. BMC Cancer. 2014;14:705.

30. Lips EH, van Eijk R, de Graaf EJ, Doornebosch PG, de Miranda NF, Oosting J, et al. Progression and tumor heterogeneity analysis in early rectal cancer. Clin Cancer Res. 2008;14:772-81.

31. Huang $N$, Wu Z, Lin L, Zhou M, Wang L, Ma H, et al. miR-338-3p inhibits epithelial-mesenchymal transition in gastric cancer cells by targeting ZEB2 and MACC1/Met/Akt signaling. Oncotarget. 2015:6:15222-34.

32. Wang L, Lin L, Chen $X$, Sun L, Liao Y, Huang N, et al. Metastasis-associated in colon cancer-1 promotes vasculogenic mimicry in gastric cancer by upregulating Twist1/2. Oncotarget. 2015;6:11492-506.

33. Guo T, Yang J, Yao J, Zhang Y, Da M, Duan Y. Expression of MACC1 and CMet in human gastric cancer and its clinical significance. Cancer Cell Int. 2013;13:121.

34. Aberle H, Schwartz H, Kemler R. Cadherin-catenin complex: protein interactions and their implications for cadherin function. J Cell Biochem. 1996:61:514-23.

35. Kauffman EC, Robinson VL, Stadler WM, Sokoloff MH, Rinker-Schaeffer CW. Metastasis suppression: the evolving role of metastasis suppressor genes for regulation cancer cell growth at the secondary site. J Urol. 2003;169:1122-33.

36. Guo J, Fan K, Xie L, Xiao J, Chen K, Hui L, et al. Effect and prognostic significance of the KAl1 gene in human gastric carcinoma. Oncol Lett. 2015; 10:2035-42.

37. Yu G, Chen Y, Ni C, Wang G, Qian J, Wang J. Reduced protein expression of metastasis-related genes (nm23, KISS1, KAl1 and p53) in lymph node and liver metastases of gastric cancer. In J Exp Path. 2007;88:175-83.

38. Abe M, Sugiura T, Takahashi M, Ishii K, Shimoda M, Shirasuna K. A novel function of CD82/KAl-1 on E-cadherin-mediated homophilic cellular adhesion of cancer cells. Cancer Lett. 2008;266:163-70.

39. Zhou L, Yu L, Wu S, Feng Z, Song W, Gong X. Clinicopathological significance of KAl1 expression and epithelial-mesenchymal transition in non-small cell lung cancer. World J Surg Oncol. 2015:13:324.

40. Zheng Z, Gao S, Yang Z, Xie H, Zhang C, Lin B, et al. Single nucleotide polymorphisms in the metastasis-associated in colon cancer-1 gene predict the recurrence of hepatocellular carcinoma after transplantation. Int J Med Sci. 2014;11:142-50.

41. Sun $L$, Duan J, Jiang $Y$, Wang $L$, Huang $N$, Lin $L$, et al. Metastasis-associated in colon cancer-1 upregulates vascular endothelial growth factor-C/D to promote lymphangiogenesis in human gastric cancer. Cancer Lett. 2015;357:242-53.

42. Liu WM, Zhang F, Moshiach S, Zhou B, Huang C, Srinivasan K, et al. Tetraspanin CD82 inhibits protrusion and retraction in cell movement by attenuating the plasma membrane-dependent actin organization. PLoS One. 2012;7(12):e51797.

43. Mela A, Goldman JE. The tetraspanin, KAl1/CD82, is expressed by latelineage oligodendroctye precursors and may function to restrict precursor migration and promote oligodendroctye differentiation and myelination. J Neurosci. 2009:29(26):11172-81. 